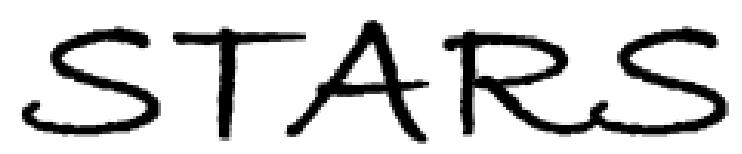

University of Central Florida

STARS

Faculty Scholarship and Creative Works

2017

\title{
CD-ROM's acquaintances: What to do with the skeletons in our academic libraries
}

Jeanne Piascik

University of Central Florida

Kristine Shrauger

University of Central Florida

Lindsey Ritzert

University of Central Florida, lindsey.ritzert@ucf.edu

Part of the Cataloging and Metadata Commons, and the Collection Development and Management Commons

Find similar works at: https://stars.library.ucf.edu/ucfscholar

University of Central Florida Libraries http://library.ucf.edu

This Paper is brought to you for free and open access by STARS. It has been accepted for inclusion in Faculty Scholarship and Creative Works by an authorized administrator of STARS. For more information, please contact STARS@ucf.edu.

\section{Original Citation}

Jeanne Piascik, Kristine J. Shrauger \& Lindsey Ritzert (2017) CD-ROM's acquaintances: What to do with the skeletons in our academic libraries, Journal of Access Services,14:3, 114-117, DOI:10.1080/ 15367967.2017.1318704

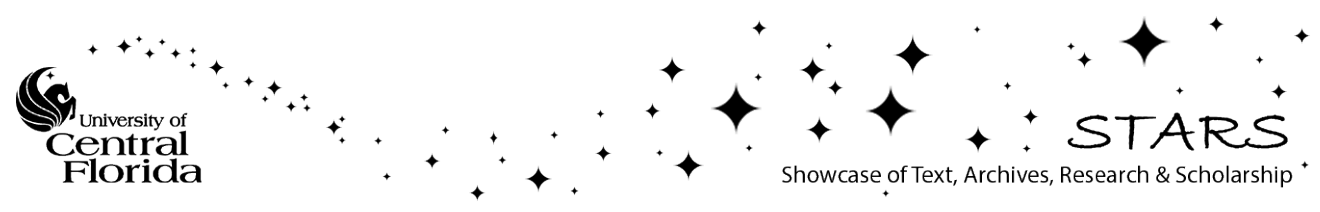


CD-ROM's acquaintances: what to do with the skeletons in our academic libraries

Authors:

Jeanne.Piascik@ucf.edu

Kristine.Shrauger@ucf.edu

Lindsey.Ritzert@ucf.edu

\section{Background:}

During the 1990s through the early 2000s, the University of Central Florida (UCF) purchased a variety of monographs and reference materials that had accompanying CD-ROMs. The CDROMs were considered an enhancement to the book, rather than a stand-alone item. The enhancements could have texts or graphics, or some sort of supporting material to the book.

A decision was made to catalog the book and the CD-ROM on one bibliographic record but have separate item records. There was one item record per barcoded pieces, so, for example the book Microsoft Commerce Server 2000 configuration and administration by Nitin Pandey, Ashok Appu and NIIT had one book and 2 CD-ROMs for a total of three item records. The CDROMs were in jewel cases with separate barcodes and housed behind the circulation desk. A sticker was placed on the lower right-hand corner of the book telling the patron to "ask for CDROM at Circulation Desk." The deciding factors to catalog and shelve the CD-ROMs separately were to increase volume number statistics, to keep the much smaller CD-ROM cases from getting lost in the stacks, and to keep the CD-ROMs from "walking away."

Over the years, UCF acquired close to 7400 CD-ROMs that accompanied books. The CDROMs took up an enormous amount of valuable space behind the circulation desk in a building that was already overcrowded. The question became, 20 years after the introduction of CDROM accompaniments, did the CD-ROMs work with today's technology? Were the CD-ROMs designed for certain software, and was the software around anymore? Did students and patrons have computers with drives that could read the CD-ROMs? What was the shelf life of the 
average CD-ROM? Were the books of historical value? Could the books be used without the CD-ROM content? The question now becomes, what do libraries do with the CD-ROMs that no longer work due to technological changes?

\section{Literature Review:}

Twenty five years ago, there were dozens of books being published on the topic of CD-ROMs such as CD-ROM in Libraries : Management issues, The Librarian's CD-ROM handbook, and Optical discs for storage and access in ARL Libraries to name a few. These books highlighted implementing, maintaining and distributing CD-ROMs across various platforms. Articles discussed the evolution of CD-ROMs in the library (Barnes, 1997), content of the CD-ROM (Shirinian and Nicholls, 1997), staff resistance to this form of technology (Giesbrecht and McCarthy, 1991), and the integration of CD-ROMs into the bibliographic instruction sessions (Blumenthal, 1993). Articles also discuss patron usage of CD-ROMs and their satisfaction with using that format (McCarthy, 1997). Nancy Herter's article CD-ROM in Libraries in June 1995 marked 10 years since the CD-ROM was introduced into libraries.

\section{Methodology:}

First, we wanted to determine other institutions' practices. An email was sent to the LibCirc PLus listserve and the Florida Academic Library Services Cooperative Circulation and Resource Sharing listserve and we received very few responses. None of the responders had accompanying CD-ROMs shelved separately from books.

Next, we needed to determine what information was required to know if a CD-ROM was still useful. We decided to use the following data: 1) whether the CD-ROM still worked on the library's PCs and network; 2) whether it still worked on a laptop not connected to the university's network; and 3) whether it had been checked out in the past 10 years. Student assistants 
reviewed the CD-ROMs for computer functionality, and a staff member identified the last time an item was checked out.

\section{The outcome:}

The project of reviewing and collecting information took a little over a year. Staff reviewed more than 7400 CD-ROMs. Circulation data was collected from 2006 to the present, since prior to then we did not have record of last checkout or return.

Books with CD-ROMs were purchased throughout the collection. The call number ranges with the greatest number of CD-ROMs were the Q's, H's and T's. These three call number ranges had approximately 5368 books with accompanying CD-ROMs. The QA range (Mathematics) alone had 2492 books with CD-ROMs. Library of Congress classifications A and V had no CDROMs. Call number ranges $F, S$, and $U$ had a grand total of 32 .

Of the 7400 titles that were reviewed, 6258 CD-ROMs had never been checked out, while 5038 books that were associated with the CD-ROMs had never been checked out. The CD-ROM for Why TESOL? : theories and Issues in Teaching English to Speakers of Other Languages in K12 Classrooms, PE1128.A2 W53 2010, had the highest circulation with 119 checkouts. There were two titles, in which the CD-ROMs were checked out more than 300 times, otherwise, the majority of CD-ROMs were only checked out once or at most twice.

While UCF began acquiring CD-ROMs in the late 1990s, the usage took until 2011 to reach a level greater than 100 titles per year. The peak year for CD-ROM circulation was in 2011-2012, and book circulation peaked between 2013-2015. 


\section{Results:}

As a result of this project we reached several collection management decisions. We withdrew any CD-ROM that was found to not be compatible with library computer software or the university network. We also withdrew any CD-ROMs that did not work. For these withdrawn CD-ROMs we made the decision to keep the books. We are keeping the CD-ROMs that still work, regardless of usage statistics.

Moving forward, any newly acquired items with CD-ROM material will be cataloged as one item and the CD-ROM will be kept in a pocket in the back of the book. Currently held CD-ROMs that still work will be matched up with the cataloged book and placed in a pocket in the back of the book for consistency.

\section{Conclusion:}

A total of 1120 CD-ROMs were withdrawn from the collection. Both the Circulation and Cataloging departments, as well as library patrons benefited from this project. Plans are currently being drawn for a new Circulation Services area. Circulation Services will occupy a decreased amount of square footage, so any space gained by eliminating CD-ROMs is useful. Improved workflows were also created within the Cataloging Department. Staff no longer have to create separate item records for both book and CD-ROM. There are also fewer labels and less physical handling of materials. Lastly, patrons no longer have to wait at Circulation for staff to locate the accompanying CD-ROM. Once they've selected their materials from the shelf, check-out is more seamless. They are also less likely to lose the CD-ROM, since they no longer have to keep track of the book, the CD-ROM, and the CD-ROM case. Patrons now have more efficient access to books with CD-ROMs. 
Barnes, John $\mathrm{H}$. One giant leap, one small step: continuing the migration to electronic journals. Library Trends, no. 3, 1997, p. 404-.

Blumenthal, Caroline, et al. The impact of CD-ROM technology on a bibliographic instruction program. [at Georgia State University]. College \& Research Libraries, vol. 54, Jan. 1993, pp. 1116.

Giesbrecht, Walter, and Roberta McCarthy. Staff resistance to library CD-ROM services. CDROM Professional, May 1991, p. 34-.

Herter, Nancy, K. 1995. CD-ROM in libraries. Online 19.3 109-.

McCarthy, Cheryl Ann, et al. "Expectations and effectiveness using CD-ROMs: what do patrons want and how satisfied are they? [at the University of Rhode Island]. College \& Research Libraries, vol. 58, Mar. 1997, pp. 128-142.

Mendrinos, Roxanne. "A CD-ROM network allows multiple users to simultaneously access discs." Electronic Learning, vol. 9, no. 7, 1990, p. 32-.

Shirian, George and Paul Nicholis. 1997. CD-ROM lending at the City of York Public Library : a four-year retrospective. Computers in Libraries. 17.1. 70-74. 